\title{
O EMPREGO DE COMPUTADORES NA HISTÓRIA (*).
}

\author{
ALTIVA PILATTI BALHANA \\ CECILIA MARIA WESTPHALEN \\ da Universidade Federal do Paraná. \\ 0. - Introdução.
}

$\mathrm{Na}$ presente Comunicação, serão focalizados exemplos do emprego de computação eletrônica em Projetos de pesquisa histórica, desenvolvidos no Departamento de História da Universidade Federal do Paraná, e que se vêm utilizando os serviços do computador IBM 1130, e do plotter 1627, do Centro de Computação Eletrônica da Universidade, órgão instalado em setembro de 1969.

\section{1. - A História, o computador e os historiadores.}

A historiografia atual, renovada metodologicamente, e aproveitando-se das modernas técnicas postas à sua disposição pelo progresso da ciência, objetiva uma História científica, dinâmica, concreta.

Assim, além das técnicas tradicionais que visam obter informações que conduzem apenas a avaliações qualitativas, decorrentes da própria abordagem qualitativa, a nova historiografia vem largamente empregando métodos, técnicas e recursos operacionais que visam obter dados e informações, direta ou indiretamente quantificáveis, acerca de tudo quanto pode ser medido ou contado na História. A sua utilização permite dispor de instrumentos de análise altamente precisos e objetivos que libertam o historiador de seus julgamentos intuitivos e limitados pelos seus quadros de referência, fornecendo bases de apoio indispensáveis às avaliações qualitativas.

Com a crescente aplicação destes novos métodos e técnicas quantitativas na pesquisa histórica, cresceram também as possibilidades de emprego de computadores no processamento de evidências históricas,

(*). - Comunicação apresentada na 4.a sessão de Estudos, no dia 7 de julho de 1972 (Nota da Redação). 
sobretudo nas áreas de História econômica, História demográtifca, História política, História urbana e outras.

As possibilidades e vantagens de estudo e análise, oferecidas pelo emprego de computadores na Históría, são de extraordinário alcance, permitindo atingir maiores profundidades e amplitudes extensas, ou sejam, o tratamento de um maior número de variáveis, para períodos mais longos de tempo, mesmo seculares, ou seja ,ainda, a observação microscópica de macro-corpus.

A abordagem quantitativa, com o emprego de computadores, permite abranger senão todas as situações, mas uma grande soma delas, e não apenas aquelas que podem, eventualmente, ocorrer ao pesquisador artesanal, enquadrado que está pelo seu instrumental lógico e operacional, atingindo, em consequencia, maior grau de complexidade, com maior grau de segurança e objetividade.

De outro lado, o emprego de métodos e técnicas quantitativas, possibilita maior aproximação conceitual e metodológica com as demais Ciências do Homem que, desde há mais tempo, as utilizam para quantificações precisas e explícitas.

Os historiadores justamente se acham em retardamento em relação aos demais cientistas sociais. Esse atraso tem tido como con'equência que cientistas políticos, economistas, demógrafos, sociólogos, e outros, têm produzido História quantitativa, enquanto os historiadores de ofício ainda relutam em praticá-la e mesmo aceitá-la, arraigados que se encontram sobretudo a preconceitos relativos à própria natureza da ciência histórica. No entanto, é certo que

“. . . anyone who is not blindly and irrevocably committed to the view that all legitimate history is ideographic rather than nomothetic, an art and no a science, should concede two points: first, that there a great many historical problems of importance which demand the analysis of overtly quantitative data (voting statistics, information on wages and princes, population figures, etc.), and second, that the fabric of even the most conventional historical account is studded with terms which are in some sense implicity quantitative ("representative", "lypical", "widespread", "intense", "growing", etc)" (1).

(1). - Thernstrom (Stephan), "The Historian and Computer", in Robert P. Swierenga, ed., Quantification in American History, New York, 1970, p. 68 . 
De modo que, antes que relutar, e mesmo rejeitar a priori, os historiadores devem realizar experimentos válidos, desde simpler aplicações até o emprego altamente sofisticado de computadores, sobretudo no campo da História do Brasil, tão marcada pela erudição e tradicionalismo, e, onde, senão em abundância inesgotável, existe material que pode fornecer evidências direta ou indiretamente quantificáveis, ainda totalmente inexploradas.

\section{2. - Primeiras experiências na História do Paraná.}

Desde que instalado o Centro de Computação Eletrônica da Universidade Federal do Paraná, e estando já em curso Projeto com $c$ emprego de técnicas quantitativas, em julho de 1970, foi iniciada a aplicação do computador no processamento de dados relativos ao Projeto n. ${ }^{\circ} 2$ - Navios e mercadorias no porto de Paranaguá, sob a direção da Professora Cecília Maria Westphalen. Objetivava-se, no tratamento da informação, nessa fase, $c$ construção de "leques de curvas", conforme metodologia proposta por J. Bertin (2). Assim, foram, de início, submetidos ao processamento, 27.600 dados positivos ou negativos, referentes ao movimento de entradas e saídas de embarcações no porto de Paranaguá, no século XIX, sua procedência e destino, tipos, nacionalidades, tonelagens, equipagens, e outros, bem como listas de mercadorias importadas e exportadas, sua proveniência e destino, quantidades, preços, e outros. Foram construídas 19 tabelas comportando 276 séries de informações, de 1801 a 1900 , que resultaram no traço de 276 curvas, sendo 223 relativas à navegação e 53 rèlativas ao comércio. A escala logarítmica adotada na construção gráfica, uma vez montadas as transparências com cada curva sobre um suporte separado, realizada a interpretação, permitiu o estudo das variações conjunturais e das tendências de longa duração, pela percepçăo da imagem visual, manipulação e reagrupamentos comparativos.

Por sua vez, desde junho de 1971, tem sido utilizada a computação eletrônica no tratamento inicial dos dados demográficos sobre a evolução da população de Curitiba no século XIX, ou seja, de resultados parciais do Projeto n. 3 - História Demográfica do Paraná, sob a direção da Professora Altiva Pilatti Balhana. Foram construídas as séries anuais de batizados, casamentos e óbitos, no total de 87.248 registros, e calculadas as medidas decenais para cada uma das

(2). - Bertin (J.), Graphique et Mathématique: Généralisation du traitement graphique de l'information, in ANNALES, Paris, 24 (1): 70-101, jan./ fev. 1969. 
séries no período estudado. Ao mesmo tempo, com os resultados preliminares obtidos, o plotter traçou as curvas que evidenciaram as flutuações do movimento de batizados, casamentos e óbitos ocorridos na Paróquia de Nossa Senhora da Luz de Curitiba, no sésulo XIX. Presentemente, estão recebendo idêntico tratamento, os dados levantados para o século XVIII, bem como nos arquivos da Comunidade Evangélica de Curitiba, e das Paróquias de Abranches e de Santa Felicidade, relativos aos imigrantes alemães, poloneses e italianos, de grande significação na formação da população de Curitiba.

\section{3. - Conclusão.}

As experiências relatadas são ainda iniciais e expressam resultados parciais. Todavia, já se pode concluir que o emprego do computador nos Projetos referidos, pode dar bases concretas de apôio para a análise e interpretação históricas, bem como permitiu realmente a manipulação de grandes quantidades de informações, de tal maneira que puderam ser inferidas regularidades que facilitam a exemplificativa nomotética na História.

Entretanto, a maior dificuldade encontrada para o seu emprego, dificuldade aliás de quase todos os historiadores que, até aqui, de modo geral, não possuem suficiente formação matemática e estatística, reside na elaboração de programas para o computador. Ela tem sido apontada, concluindo-se:

"Rather we must ultimately invent a methodology including computer programs-of our own, a methodoly desidgned to cope which the peculiar kinds of evidence with which we deal" (3).

Este é o problema fundamental a ser resolvido, pois o historiador do futuro

"sera programmeur ou ne sera pas" (Le Roy Ladurie) (4).

(3). - Zemsky (Robert M.), "Numbers and History: The Dilemma of Measurement", in Computers and the Humanities, III (sept., 1969), p. 39.

(4). - Citado por Fernand Braudel in Ecrits sur l'Histoire, p. 7, Paris, Flammarion, 1969. 